\title{
O DESAFIO DA EVASÃO EM CURSOS SUPERIORES NA
}

\section{MODALIDADE EaD.}

\author{
https://doi.org/110.29327/3860.11.20-5
}

\author{
Rafael Alves Pedrosa ${ }^{1}$ \\ Danilo Nunes ${ }^{2}$
}

\section{RESUMO}

A evasão em cursos da modalidade a distância é um dos principais obstáculos enfrentados

pelas instituições. Nesse cenário, se incluem os cursos superiores que vem sendo ofertados pela Universidade Virtual do Estado de São Paulo - UNIVESP. Este trabalho teve como objetivo analisar as causas da evasão em cursos superiores ofertados na modalidade a distância. Para tanto, 100 alunos evadidos desses cursos completaram, de maneira online, perfil social, comportamento e atitudes do aluno em relação a cursos a distância são abordados no questionário. Os resultados apontam que uma parcela importante dos evadidos realizava outras tarefas concomitantes com o curso; ainda expõem que dos evadidos boa parte dos entrevistados apresentava dificuldades de iteração com as plataformas utilizadas no processo de aprendizagem, além de mapeamento do perfil social destes indivíduos. Como conclusões estão: o fato de que o $\mathrm{EaD}$ é uma realidade e conforme aponta este estudo com viés de crescimentos acentuado no próximos anos, mas também indica a necessidade de evolução nos processos e na relação com os alunos possibilitando não somente seu acesso ao EaD mas seu efetivo aproveitamento e permanência nos cursos e instituições, sejam elas públicas ou privadas que ofereçam essa modalidade de ensino, e ainda a necessidade da realização de novos estudos que possam dar continuidade ao mapeamento e apontamento de soluções à inclusão ou exclusão de itens que aumentem a confiabilidade do EaD e minimizem os fatores identificados como causadores da evasão.

PALAVRAS-CHAVE: Evasão; EAD; Ensino Superior

\footnotetext{
${ }^{1}$ Graduado em Administração (UNIP), Comércio Exterior (USJT), Gestão Portuária (USJT) e Logística e Transportes (USJT). Pós Graduado em Docência do Ensino Superior (FGV), Gestão de Comércio Exterior e Logística (USJT). Mestre em Gestão de Sistemas Costeiros pela (UNISANTA). Doutorando em Planejamento e Gestão pela Universidade Federal do ABC (UFABC). É docente de ensino superior há 10 anos, com atuação nas seguintes universidades: UFABC, UNIBR, UNISANTA e USJT e coordenador de cursos de Pós Graduação (Lato Sensu).

${ }^{2}$ Graduado em Administração (UNILUS). Pós Graduado em Produção e Qualidade (FECAP), Recursos Humanos e Planejamento (UNIMONTE). Mestre em Administração pela (UNIMONTE). Doutorando em Administração pela Pontifícia Universidade Católica (PUC-SP). Coordenador de cursos de graduação e pós graduação, Diretor da faculdade UNIBR e exerceu o cargo de Pró Reitor acadêmico da UNIMONTE.
} 


\title{
THE CHALLENGE OF EVASION IN HIGHER EDUCATION COURSES IN THE MODALITY OF EAD.
}

\begin{abstract}
The evasion in distance courses is one of the main obstacles institutions. In this scenario, it includes the upper courses that have been offered by the Virtual University of the State of São Paulo - UNIVESP. This study had as objective to analyze the causes of evasion in superior courses offered in the distance modality. In order to do so, 100 students evaded these courses completed, so online, social profile, behavior and attitudes of the student in relation to distance learning courses are covered in the questionnaire. The results indicate that a significant portion of the escaped performed other tasks concurrent with the course; even expose that escaped the good part of the interviewees presented difficulties of iteration with the platforms used in the learning process, as well as mapping of the social profile of these individuals. As conclusions are: the fact that the EaD is a reality and as points this study with bias of sharp growth in the coming years, but also indicates the need for changes in processes and in relationship with students enabling not only their access to $\mathrm{EaD}$ but its effective utilization and permanence in the courses and institutions, be they public or private, who offer this type of education, and also the need of further studies that may give continuity to mapping and solutions pointing to the inclusion or exclusion of items that increase the reliability of $\mathrm{EaD}$ and minimize the factors identified as the cause of the circumvention.
\end{abstract}

KEYWORDS:Evasion; EAD; Higher Education

\section{INTRODUÇÃO}

A evasão é um fenômeno enfrentado não somente pelos cursos presenciais, como também pelos cursos ofertados na modalidade a distância (EAD). Segundo o Censo EAD Brasil, realizado em 2016, o fenômeno da evasão foi apontado como o maior obstáculo enfrentado pelas instituições que oferecem cursos nessa modalidade. Assim, o abandono nessa modalidade de ensino representa uma preocupação atual por parte das instituições interessadas em oferecer cursos a distância, bem como, por parte daquelas que já oferecem.

A evasão de alunos é um fenômeno complexo, comum às instituições de ensino no mundo contemporâneo. A evasão estudantil no ensino superior é um problema internacional que afeta o resultado dos sistemas educacionais (SILVA FILHO et al, 
2007).

O modelo de EAD no Brasil vem ganhando lugar de destaque e tendo maior credibilidade de acordo com o Anuário Estatístico AbraEAD (2017), nos últimos três anos o número de instituições que ofertam cursos a distância no Brasil cresceu 54,8\%.

Tal curva de crescimento ainda tende a se acentuar tendo em vista que conforme o referido estudo, até 2026, os cursos a distância vão ultrapassar o ensino presencial em número de alunos. Do total de 9,2 milhões de estudantes que estarão matriculados em instituições privadas naquele ano, $51 \%$ deles estarão inscritos em cursos online. (KUZUYABU, 2017)

O crescimento do EAD, segundo Santos et al. (2008), está associado à busca por conhecimentos e educação ao longo da vida, atributos estes que são reconhecidos como elementos fundamentais para o desenvolvimento humano e social. Esse aumento ocorre devido o EAD ser mais flexível do que os modelos tradicionais de educação, possibilitando uma melhoria na qualidade do processo educativo (NEVES, 2006). Para Belloni (2009), significa, fundamentalmente, rever e tornar menos estrito os requisitos de acesso ao ensino, para o aluno estudar a distância.

A evasão de alunos no EAD tem sido abordada como um dos problemas que está muito presente em todas as instituições educacionais e em todos os níveis de ensino. São vários os motivos que levam as instituições, sejam elas públicas ou privadas, a ter maior preocupação com o problema da evasão no EAD. De acordo com Motejunas et al. (2007), os problemas de cursos no EAD são: para o setor público, os recursos investidos sem o devido retorno; para o setor privado, importante perda de receita; para ambos os setores, fonte de ociosidade de professores, funcionários, equipamentos e, em algumas situações, espaço físico.

No Brasil são poucos os estudos sistemáticos e dados nacionais sobre evasão. De acordo com Biazus (2004), as pesquisas sobre evasão escolar limitam-se mais ao ensino fundamental e médio, o que não traz muita diferença, visto que a baixa qualidade do ensino básico brasileiro, traduzida pelos altos índices anuais de repetência e evasão escolar, reflete os defeitos históricos da própria sociedade brasileira, que é excludente, segundo Garschagen (2007, p. 35).

No EAD existe uma preocupação muito maior frente à evasão, pois, segundo o anuário estatístico da AbraEAD (2017), por oferecer oportunidade de estudo no 
ambiente doméstico, social ou profissional, e ainda por permitir que o aluno escolha os horários em que vai estudar, no EAD geralmente possui mais estímulos concorrenciais (filhos, mulher, barulho de televisão e da vizinhança entre outros) e depende de forma bem mais direta de algumas aptidões do aluno, como capacidade de organização e de concentração para os estudos.

Consideram-se evadidos os alunos que, após terem se matriculado, nunca se apresentaram ou se manifestaram de alguma forma para os colegas e mediadores do curso, em qualquer momento (FAVERO, 2006). Toczek et al. (2008) definem como o desligamento ou abandono do aluno da instituição de ensino e, para Unesco (2009) consiste de um processo individual podendo se constituir em fenômeno coletivo, dependendo das circunstâncias.

As diversas possibilidades proporcionadas pelo EAD à sociedade, sugerem às instituições educacionais um movimento de adaptação a essa tendência como condição de sobrevivência no mercado educacional.

Afim de conhecer melhor os porquês da evasão, a Educa Insights realizou uma pesquisa com algumas IES que ofertam EAD e um dos aspectos que mais pesam na permanência dos alunos é o relacionamento entre instituições e estudantes. A falta de contato, segundo a pesquisa é um dos fatores que leva à evasão dos estudantes. Contatou-se que as instituições que conseguiram manter uma proximidade com os alunos, foram as que obtiveram êxito no controle e diminuição da evasão. Outro fator relevante foi a infraestrutura dos polos e a logística dos mesmos. (TOKARNIA, 2017)

Hoje, a maior parte das matriculas em EAD estão concentradas no ensino superior privado, com cerca de $91 \%$ conforme Censo/2015. Mas os governos já começam a sinalizar investimentos para essa modalidade, como é o caso do Governo do Estado de São Paulo, com a UNIVESP, fruto da integração das três universidades públicas do Estado, USP, UNESP e UNICAMP, universidade esta contemplada na pesquisa de campo que embasa este estudo.

Destarte, a presente pesquisa teve por objetivo refletir e analisar as causas da evasão em cursos superiores ofertados na modalidade $\mathrm{EaD}$.

\section{FATORES CAUSADORES DE EVASÃO NA EaD}

Xenos et al. (2002) classificam os fatores da evasão em cursos a distância em 
fatores internos, fatores relativos ao curso e tutores e os fatores demográficos do estudante. Os fatores internos se referem às percepções do aluno e seu locus de controle, englobando a percepção acerca da dificuldade do conteúdo do curso ou do curso em si próprio, a falta de motivação do aluno, a pouca persistência do mesmo e seu locus de controle interno-externo; já os fatores relativos ao curso e aos tutores dizem respeito às características do curso (presencial, semipresencial, carga horária, material didático etc) e dos tutores (qualidade da interação dentre outros); e os fatores demográficos do aluno, tais como idade, sexo, estado civil, número de filhos, tipo de trabalho ou profissão etc..

Coelho (2002) realizou uma pesquisa exploratória sobre as causas da evasão em cursos na modalidade EAD. Os achados apontam que o principal fator para a desistência do curso é a falta de tempo e o insuficiente domínio técnico no uso das novas tecnologias, como computador, Internet e Ambientes Virtuais de Aprendizagem (AVA).

Em 2003, Zerbini (2003) encontrou em sua pesquisa empírica que as características dos alunos assumem maior impacto na determinação da evasão. Aspectos como organização, disciplina, gestão do tempo e automotivação são relevantes para a manutenção ou a desistência do curso. A falta de interação no mural de notícias, fóruns, chats e mensagens eletrônicas correlacionaram com alunos que não concluíram curso a distância (Abbad, Carvalho e Zerbini, 2006). Shannon e Bylsma (2006 in Santos et al., 2008) também enumeram fatores causais para o mesmo fenômeno: condição socioeconômica, formação e domínio acadêmicos pobres, cursos totalmente a distância ou com poucos encontros presenciais, reprovações em disciplinas, problemas familiares, baixa autoestima, currículo pouco relevante ou limitado, estratégias instrucionais passivas, inadequação ou inexperiência no uso das tecnologias e desrespeito aos estilos de aprendizagem dos estudantes.

Ora, uma vez que o EAD vem crescendo consideravelmente no cenário educacional do Brasil e do mundo, e também apresentando um índice alarmante de evasão entre os seus alunos, Belloni (2003) sugere que as instituições provedoras de educação aberta e a distância, precisam trabalhar para superar tal obstáculo. A autora vai além e indica que a direção é focar: "mais em questões de ordem socioafetiva do que propriamente em conteúdos ou métodos de cursos, mais em estratégias de contato e interação com os estudantes do que em sistemas de avaliação e de produção de materiais" (Belloni, 2001, p. 45 - 46). 
Muitos alunos tendem a se evadirem de um curso na modalidade a distância por não estarem adequados e preparados para quebrar paradigmas educacionais. Para Peters (2004, p. 48), uma "mudança de paradigma na educação" poderia significar que na educação certos modelos ou padrões não existem mais porque novos modelos e padrões que diferem dos antigos de modo marcante os substituíram.

Estudos de Zerbini e Abbad (2008), Gaioso (2005), Shin e Kim (1999) indicam que o fenômeno da evasão tem dois tipos de causas categorizadas como endógenas e exógenas.

As causas endógenas da evasão na $\mathrm{EaD}$ são: requisitos didáticos pedagógicos, motivos institucionais e atitudes comportamentais. As subcategorias estão relacionadas ao aluno quando ele já está na universidade e cursando algum curso. Para Jensen e Almeira (2009)

\begin{abstract}
Problemas de contato, feedback com os tutores, dificuldade de acesso ao material disponibilizado pelos tutores e dificuldade de acesso a material didático fora do ambiente virtual, plataforma de informática deficiente, muito improviso nos encontros presenciais, falta de integração da universidade com as necessidades locais e com a qualidade da educação, o curso possui muita carga filosófica para pouco suporte técnico, fundamentos teóricos distantes da necessidade das escolas do interior do país, tempo de duração do curso, o curso deveria ser totalmente a distância e o curso deveria ter trabalhos só individuais ou trabalhos em grupo apenas nos encontros presenciais.
\end{abstract}

As instituições aumentam os seus custos de prevenção e de outro lado o aluno não se sente prejudicado por não ter suas expectativas atendidas, evitando assim que este se evada de um curso a distância. Mensurar os custos da qualidade não é uma tarefa comum nas instituições, até porque esta categoria de custo não aparece totalmente nos registros contábeis. Segundo Pereira (2003), é possível utilizar um conjunto de estratégias para correção das falhas. Para isso é preciso definir quais são as causas e os motivos que estão levando às falhas. Nesse estudo trabalhamos com as subcategorias das causas endógenas, de acordo com o quadro 1, pelas quais os alunos poderão evadir do curso.

Quadro 01 - Causas endógenas da evasão em EAD

\begin{tabular}{|c|l|}
\hline \multicolumn{2}{|c|}{ Atitude comportamental } \\
\hline Didática dos professores & $\begin{array}{l}\text { Parte do princípio que o } \\
\text { aluno a distância é diferente } \\
\text { do presencial e o contato e a } \\
\text { didática dos professores e } \\
\text { Orientação da coordenação do curso } \\
\text { tutores têm de ser voltada e } \\
\text { focadivação e incentivo por parte do tutor }\end{array}$ \\
\hline Insatisfação com o tutor & \\
\hline Contato com os professores &
\end{tabular}




\begin{tabular}{|c|c|}
\hline \multicolumn{2}{|c|}{ Motivos institucionais } \\
\hline Ausência de tutores nos polos & \multirow{7}{*}{$\begin{array}{c}\text { Proporciona ao aluno } \\
\text { condições para o estudo. Com } \\
\text { uma estrutura para que o } \\
\text { aluno possa ter acesso a } \\
\text { bibliotecas e laboratórios }\end{array}$} \\
\hline Acesso a bibliotecas & \\
\hline Estrutura dos polos de ensino & \\
\hline Laboratórios de informática & \\
\hline Interatividade no AVA & \\
\hline Meios de comunicação oferecidos & \\
\hline Tecnologia inadequada utilizada & \\
\hline \multicolumn{2}{|c|}{ Requisitos didático-pedagógicos } \\
\hline Carga horária curricular do curso & \multirow{15}{*}{$\begin{array}{l}\text { Estimula a cooperação e } \\
\text { relação entre os alunos do } \\
\text { curso, estimulando uma } \\
\text { criação de rede colaborativa } \\
\text { que dê subsídios para a } \\
\text { aprendizagem dos alunos. } \\
\text { Deve possibilitar um } \\
\text { feedback ao aluno imediato } \\
\text { de suas atividades e ações do } \\
\text { curso. Com o devido retorno, } \\
\text { os tutores e professores } \\
\text { podem identificar as } \\
\text { possíveis causas de erros nas } \\
\text { atividades. }\end{array}$} \\
\hline Relação do currículo com o mercado & \\
\hline Critérios de avaliação do aluno & \\
\hline Associação entre teoria e prática & \\
\hline Relação entre conteúdos das disciplinas & \\
\hline Encontros presenciais & \\
\hline Complexidade das atividades & \\
\hline Contato entre colegas de curso & \\
\hline Reprovação em disciplinas & \\
\hline Prazo de entrega das atividades & \\
\hline Avaliação dos exercícios & \\
\hline Avaliação das provas & \\
\hline Material didático oferecido & \\
\hline Qualidade do curso & \\
\hline Falha de elaboração do curso & \\
\hline
\end{tabular}

Fonte: BIAZUS (2004), adaptado pelos autores

As causas exógenas da evasão no EAD, segundo Biazus (2004) e Pacheco (2007), estão relacionadas com fatores externos à instituição e ao curso que o aluno está. Estes fatores podem estar ligados a problemas sócio-político-econômicos, vocação pessoal, características individuais e conjunturais que possam vir a impedir ou dificultar a permanência do discente em seu curso.

Na prática o ponto central das causas exógenas é o fato de que a instituição não tem poder sobre o estudante para evitar esse tipo de evasão, mas pode atuar na sua minimização, trabalhando as causas com os discentes, traçando um perfil do estudante ao entrar na universidade, procurando identificar possíveis causas e consequentemente as tratar quando possível.

O problema da evasão é agravado devido aos poucos trabalhos de combate à 
evasão de alunos em cursos desta modalidade de ensino. Outro problema está no cálculo feito pelas IES para caracterizar os alunos evadidos que, segundo Rumble (2003), são contabilizados como alunos regulares somente aqueles que após a matrícula frequentam pelo menos dois meses de curso, ou seja, os alunos que apenas se matriculam e os que só participam das aulas por um período inferior a esse não são inclusos como alunos dessa IES, não sendo contabilizados assim como alunos evadidos da mesma. Isso reflete nas baixas taxas de conclusão de alunos na $\mathrm{EaD}$ e nos altos índices de evasão.

Muitos alunos que se matriculam nos cursos a distância adquirem o material didático e simplesmente não interagem e nem aparecem para os encontros presenciais. Como caracterizar esse aluno, evadido ou não evadido? Como saber o porquê de esse aluno não aparecer nos encontros? O que fez esse aluno não interagir no curso? Como proceder se a instituição não teve a oportunidade de avaliar esse aluno? Como caracterizar esses abandonos. São questões complexas de serem respondidas.

Para Aretio (1998; 2002), existem dois tipos de abandono na EaD: abandono real e abandono sem começar, ou seja, alunos sem começar são aqueles que não existe nenhum registro de atividade, avaliação, teste e/ou prova em qualquer disciplina do curso matriculado. Já o abandono real é caracterizado pelo aluno que faz a matrícula no curso e no decorrer de algum período ou ano deixa de concluir os estudos. Existe uma grande diferença entre os dois tipos de abandono, que deve ser analisado pelas instituições na hora de fazer os cálculos de evasão. Segundo Pacheco, Melo e Moretto Neto (2007) os cálculos com base no abandono real aproximasse em porcentagem aos cursos presenciais, ou seja, não existem grandes diferenças de evasão do ensino presencial para a distância. Se comparados os índices são bem próximos.

\section{DELINEAMENTO METODOLÓGICO}

No tocante à abordagem do problema, a presente pesquisa é classificada como quantitativa, porque procura explorar os dados e aplicar a análise estatística dos mesmos possibilitando a análise do cenário estudado (MALHOTRA, 2001).

Quanto aos objetivos, o estudo se caracteriza como descritivo, pois tem por finalidade, “descobrir, com a precisão possível, a frequência com que um fenômeno ocorre, sua relação e conexão com outros, sua natureza e características" (CERVO \& 
BERVIAN, 1996, p.49). Uma de suas características mais significativas é a utilização de técnicas padronizadas de coleta de dados (GIL, 1999).

A pesquisa descritiva objetiva conhecer e interpretar a realidade sem nela interferir para modificá-la (CHURCHILL, 1987), expondo as características de determinada população ou de determinado fenômeno, mas não tem o compromisso de explicar os fenômenos que descreve, embora sirva de base para tal explicação.

Para o alcance dos objetivos, primeiramente o estudo foi baseado no levantamento bibliográfico sobre o tema e foram analisadas as informações contidas no site da UNIVESP, consideradas fontes secundárias.

O universo da pesquisa foi composto por discentes evadidos da Universidade Virtual do Estado de São Paulo, num total de 100 pessoas.

O questionário foi elaborado, enviado e aplicado online, entre os meses de agosto a outubro de 2017, para os alunos evadidos, utilizando-se a plataforma Google Docs.

Os dados foram tratados por estatística descritiva, por intermédio de análise de distribuição de frequência, apresentação de gráficos e tabelas, identificando características da amostra e relação entre as variáveis qualitativas do estudo.

\section{O DESENVOLVIMENTO DO ESTUDO}

Este estudo foi conduzido na Universidade Virtual do Estado de São Paulo UNIVESP, que tem por objetivo atender às demandas da sociedade paulista por meio da oferta de cursos de diversas áreas do conhecimento, em ensino superior (graduação), e tem por missão: "Ampliar o acesso ao ensino superior público gratuito e de qualidade". A UNIVESP vem ofertando cursos superiores a distância de: Engenharia de produção, Engenharia da Computação, Pedagogia e Licenciaturas em Física, Química, Biologia e Matemática.

O público alvo é formado pelos interessados em geral, exigindo-se o ensino médio completo e classificação em processo seletivo. Quanto aos materiais didáticos utilizados no curso, estes são disponibilizados em um Ambiente Virtual de Aprendizagem (AVA), especialmente desenhado para as graduações da UNIVESP.

Cabe ressaltar que o estudo se deu com discentes evadidos dos polos da Região 
Metropolitana da Baixada Santista (RMBS), que conta com polos nas cidades de Santos, Cubatão, São Vicente, Mongaguá e Peruíbe. Nestes polos a oferta de cursos fica restrita apenas aos cursos de Engenharias de Produção e Computação, Pedagogia e Licenciatura em Matemática.

\subsection{DISCENTES EVADIDOS POR CURSO}

A população desta pesquisa abrangeu um grupo de ex-alunos provenientes dos 4 cursos supracitados. No total, registrou-se a evasão de $39 \%$ do total de matriculados. Cabe registrar que 115 alunos responderam à pesquisa. Após uma primeira análise, verificou-se que 15 alunos desistiram do curso antes do início das aulas, logo, não foram

incluídos na amostra. Os 100 participantes restantes compuseram a amostra desta pesquisa, conforme mostra a Figura 1:

Figura 01 - Discentes evadidos por curso

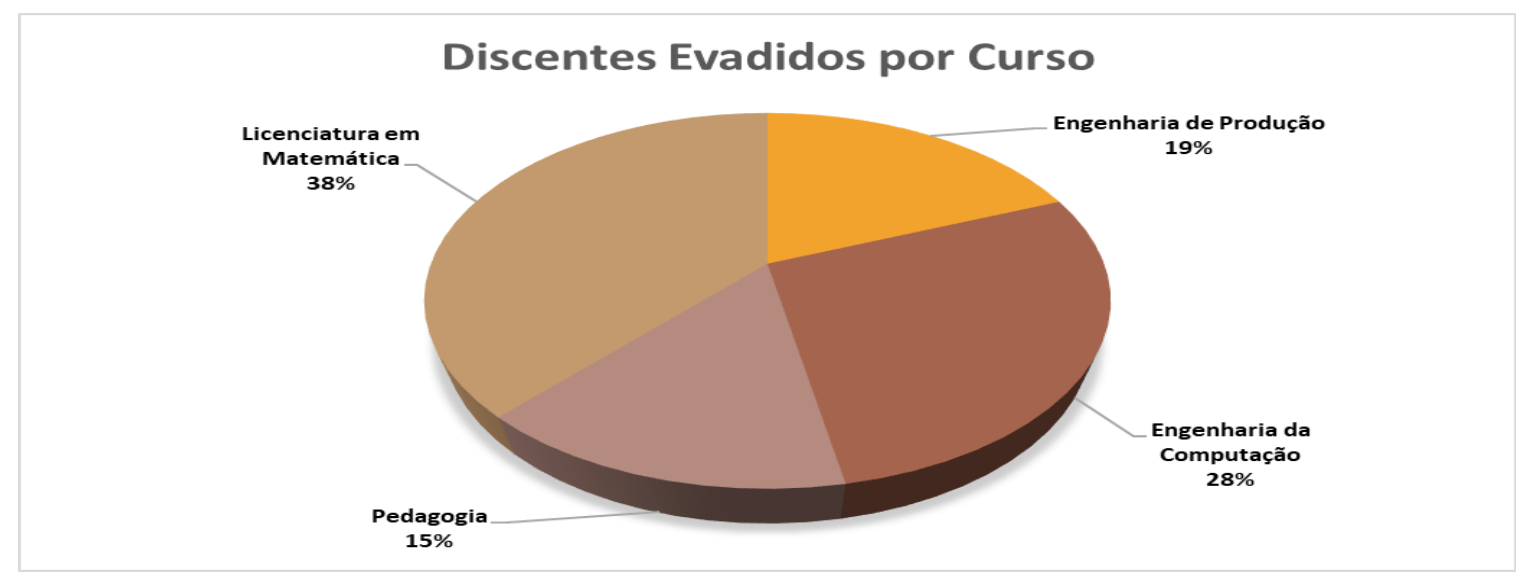

Fonte: elaborado pelos autores

Quanto ao perfil desse grupo, a maior parte dos participantes é composta por indivíduos casados ou em união estável que somam (63\%); possuem ensino superior incompleto (43,5\%); e são funcionários públicos do governo federal, estadual ou municipal (41\%) da amostra entrevistada neste estudo.

\section{RESULTADOS E DISCUSSÃO}

As causas de evasão envolvem uma série de variáveis complexas que tornam muito difíceis de explicar o porquê de o aluno evadir de um curso. Segundo Pereira 
(2003), a evasão não se constitui um fenômeno novo, ou seja, nem todas as pessoas que ingressam em um curso superior o concluem. O governo busca incessantemente a disseminação do ensino superior e a qualificação com a formação de professores com a utilização do EAD. Isso faz com que o governo tenha uma preocupação ainda maior com os índices de evasão, pois o fenômeno adquire uma importância muito grande, dada sua complexidade e abrangência. Não se percebe, de uma forma sistemática, movimentações das IES para formar uma comissão para estudar, identificar e monitorar os índices de evasão dos cursos a distância.

Segundo Umekawa \& Zerbini (2015), pesquisas sobre o fenômeno da evasão no EAD demonstram que as características sociodemográficas do alunado são importantes para o entendimento da presença destes indivíduos nos cursos. Essas variáveis vêm sendo amplamente discutidas sendo compreendidas como facilitadores ou dificultadores à permanência dos alunos nos cursos dessa modalidade. Assim, é importante para as Instituições de Ensino Superior que oferecem cursos na modalidade $\mathrm{EaD}$, que realizem pesquisas sobre o perfil dos alunos ingressantes nos cursos, para que as ações instrucionais sejam planejadas e implementadas com base nas características da clientela (ABBAD, 2005).

O conjunto de questões sobre a caracterização do perfil dos respondentes apresenta dados em relação ao sexo, idade, renda familiar e estado civil.

A amostra pesquisada demonstrou que a representação masculina (81\%) é relevantemente superior à representação feminina (19\%). Já no tocante à idade, a maioria dos respondentes encontra-se na faixa dos 35 a 44 anos, tanto para o sexo feminino (10\%) quanto para o sexo masculino (31\%). A segunda maior representatividade de idade está na faixa de 25 a 34 anos para o sexo feminino (5\%) e de 45 a 54 anos para o sexo masculino (24\%), conforme mostra a figura 02 : 

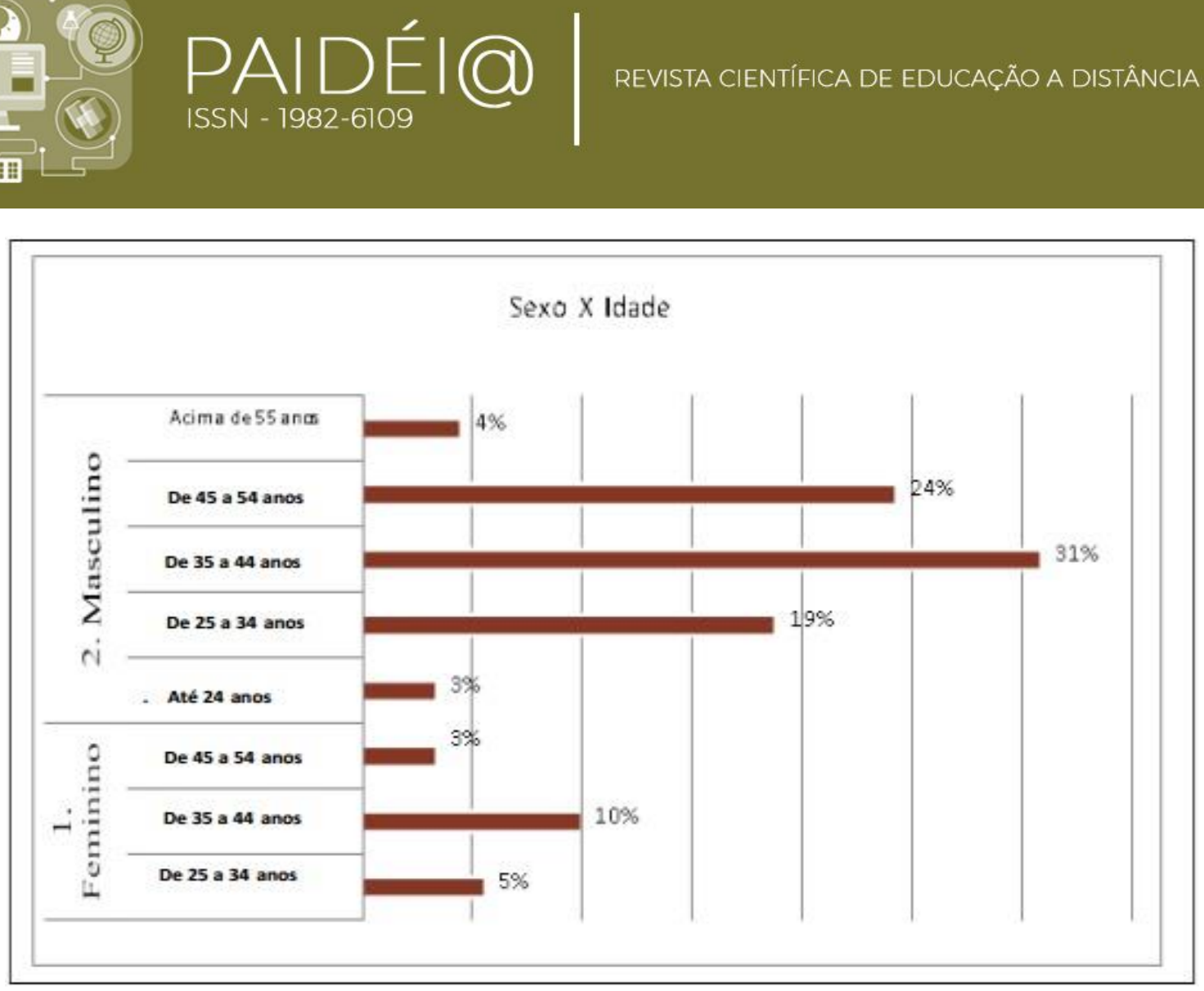

Fonte: Elaborada pelos autores

Ao mapear a renda familiar dos pesquisados, observou-se um predomínio maior daqueles que tem renda de até 5 salários mínimos (71\%), onde estão englobadas as famílias que possuem renda familiar entre 1(hum) e 3 (três) salários mínimos (42\%) e as famílias que possuem rende entre 3 (três) e 5 (cinco) salários mínimos, conforme demonstrado na figura 03 :

Figura 03 - Renda familiar dos entrevistados

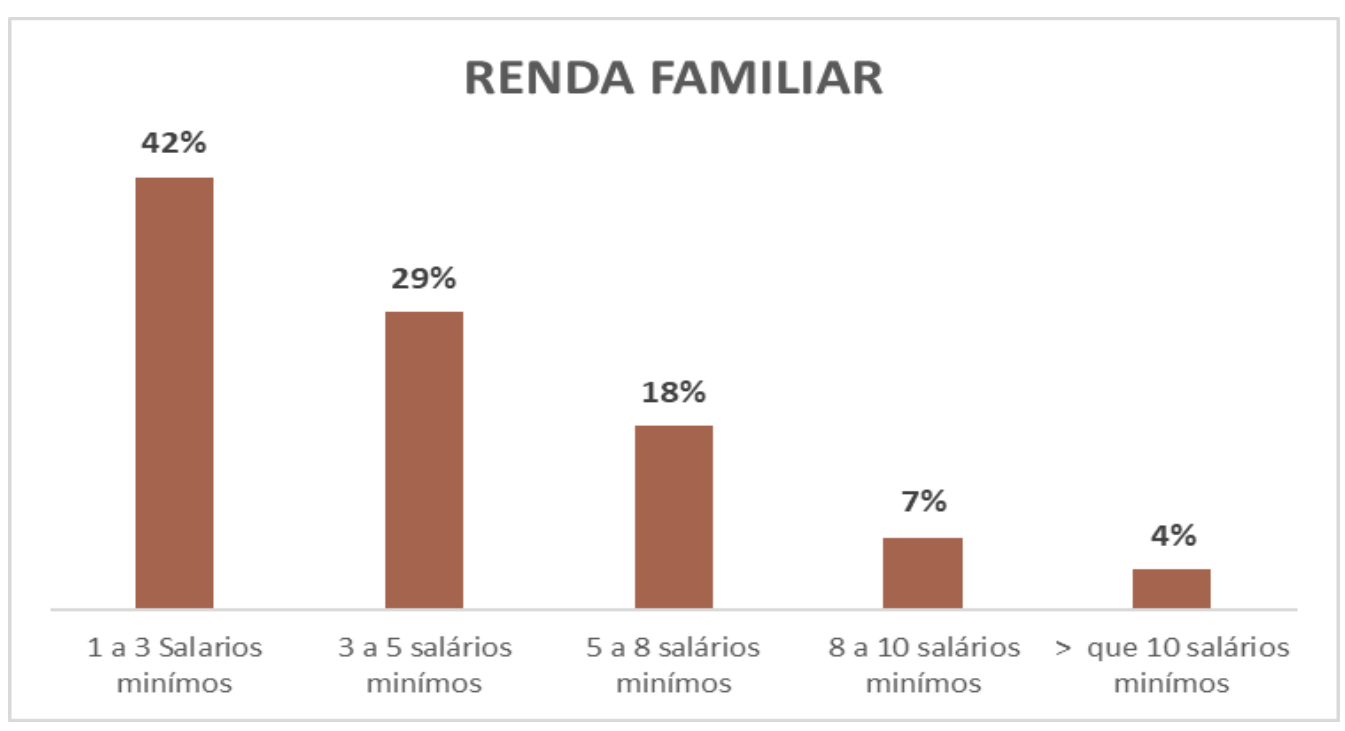


Fonte: Elaborada pelos autores

Já os resultados quanto ao estado civil, há um predomínio daqueles que são casados ou têm união estável (68\%), o que sinaliza uma tendência da estrutura familiar pesando na escolha de um curso a distância, conforme ilustra a figura 04:

Figura 04 - Estado civil dos entrevistados

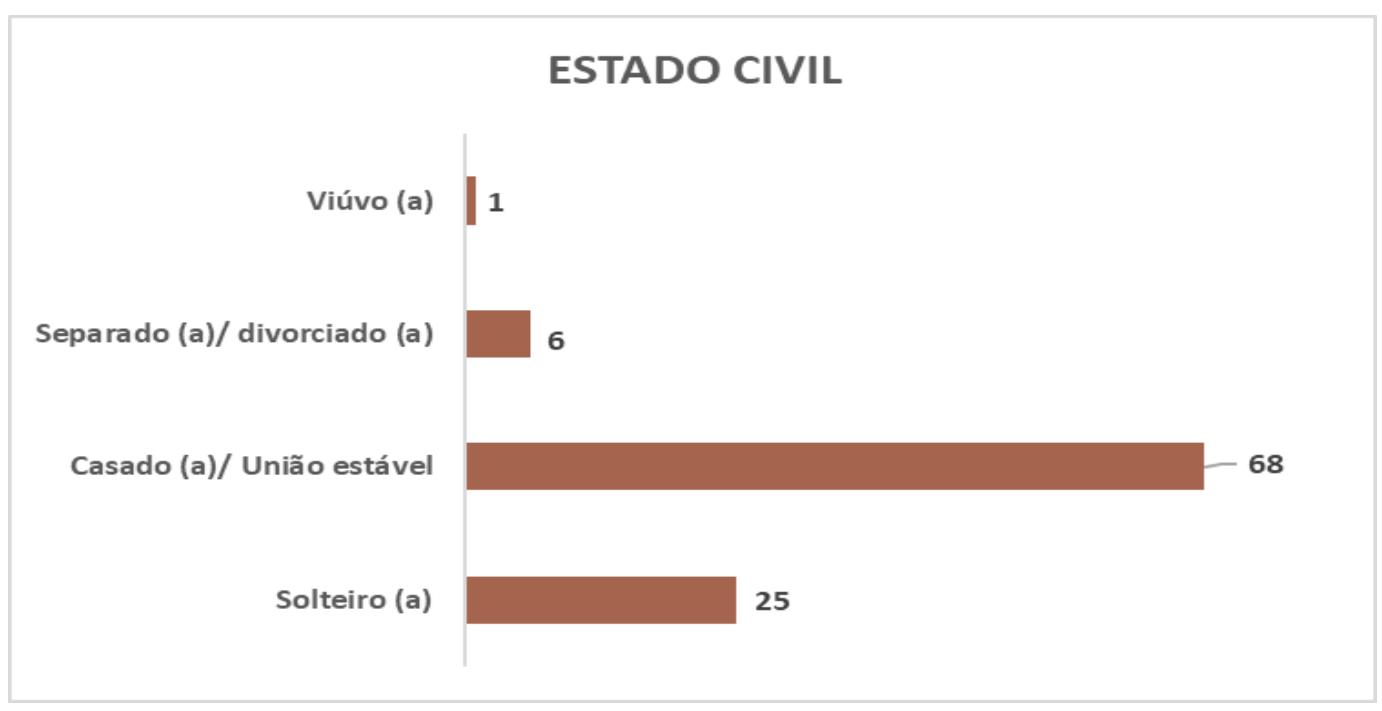

Fonte: elaborado pelos autores

No quadro a seguir, demonstrou-se as principais condições que configuram o perfil dos alunos evadidos nos cursos superiores em EAD da UNIVESP.

Quadro 02 - perfil do discente

\begin{tabular}{|c|c|c|c|}
\hline Perfil do discente pesquisado & $\begin{array}{c}\text { Sim } \\
\%\end{array}$ & $\begin{array}{c}\text { Não } \\
\%\end{array}$ & $\begin{array}{c}\text { N/A } \\
\%\end{array}$ \\
\hline Condição & $\mathbf{9 6}$ & 04 & X \\
\hline Trabalhava enquanto fazia o curso & $\mathbf{7 2}$ & 28 & X \\
\hline Dificuldades financeiras no período do curso & 34 & $\mathbf{6 6}$ & X \\
\hline Fazia outro curso simultaneamente & $\mathbf{8 7}$ & 06 & 07 \\
\hline Conhecia previamente a rotina de um aluno de EAD & $\mathbf{6 4}$ & 21 & 15 \\
\hline Dificuldades com o uso do chat e fóruns & 03 & $\mathbf{8 8}$ & 09 \\
\hline Dificuldades com o uso de e-mail & $\mathbf{4 7}$ & 32 & 21 \\
\hline Dificuldades no deslocamento até o polo & 39 & $\mathbf{6 1}$ & X \\
\hline Residia no mesmo município do polo & 12 & $\mathbf{6 8}$ & 20 \\
\hline Mantinha rotinas de estudos diárias ou semanais & & & \\
\hline
\end{tabular}


Tinha alguma experiência anterior com o EAD

05

$95|X|$

Fonte: elaborado pelos autores

Destarte percebe-se, pelos resultados, que as características gerais que delineiam o perfil de um discente, no caso pontualmente os evadidos na instituição e cursos pesquisados, não diverge muito dos alunos presenciais, conforme pode se acompanhar nos Censos e pesquisas publicadas a respeito. Mas, há indicadores que precisam ter um olhar mais pontual, por exemplo, 95\% dos estudantes não tinham nenhuma experiência anterior com EAD, ou $68 \%$ não conseguem organizar uma rotina especialmente dedicada aos seus estudos, ou 88\% apresentam alguma dificuldade com tecnologias, as mais comuns, como o uso de e-mail. Estes dados se não suficientes, mas são indicadores importantes para não deixarmos os alunos sem um acompanhamento efetivo por parte das instituições.

\section{CONSIDERAÇÕES FINAIS}

Podemos a partir deste estudo perceber que o EAD deixa de ser uma incógnita, um modismo ou todas as atribuições que possam ser feitas a essa modalidade de ensino. Este estudo e os atuais números do ensino superior demonstram essa realidade. Fazendo-se necessário entender as características que norteiam essa modalidade e, uma delas, é entender e conceber que não se trata de uma modalidade intercambiável como a presencial. $\mathrm{O}$ aluno de EAD enfrenta uma rotina complexa, difícil e quase sempre solitária, quando a sala de aula e o computador, ou a tecnologia utilizada, se confundem ou se fundem a ele próprio. É possível afirmar que as formas como são apresentados os conteúdos, conciliadas como esse isolamento, bem como com a inesperada, mas real complexidade, sejam relevantes para os indicadores atuais de evasão. $\mathrm{O}$ aluno simplesmente desiste e a grande questão é como nos aprofundarmos e conhecermos os principais motivos para que possamos ter políticas institucionais que não só acompanhem esses indicadores, mas que estabeleçam ações que venham a inibi-los. Todos ganham com a diminuição da evasão, o aluno, a instituição e a educação como um todo. Reinventar modelos que apostem preponderantemente na flexibilidade, podem desorientar o aluno e não nos parece esse o caminho mais adequado. São necessários 
processos que potencializem uma aproximação maior dos alunos com as instituições, onde fica clara a necessidade de se interagir a experiência para geração de novos conhecimentos. O ensino a distância não pode e nem deve ser visto como concorrente do ensino presencial, mas sim, como uma forma diferente de se aprender atendendo a um público com necessidades especificas e diferenciadas. O EAD é um grande aliado das mudanças culturais que emergem de uma sociedade digitalizada e conectada.

\section{REFERÊNCIAS}

ABBAD, G.; CARVALHO, R.; ZERBINI, T. Evasão em curso via Internet: explorando

variáveis explicativas. RAE-eletrônica, v. 5, n. 2, Art 17, 2006. Disponível em: < http://www.scielo.br/pdf/raeel/v5n2/v5n2a08.pdf>. Acesso em: 08 ago. 2018

ABED. Censo da Educação à Distância 2016 - Notas Estatísticas. Disponível em: <http://abed.org.br/censoead2016/Censo_EAD_2016_portugues.pdf>. Acesso em: 27 dez. 2017. ABRAEAD. Anuário Brasileiro Estatístico de Educação Aberta e a Distância. 2008. Anuário Brasileiro Estatístico de Educação Aberta e a Distância 2008. 4. ed. São Paulo: Instituto Monitor, 2008. Disponível em: < http://www.abraead. com.br/anuario/anuario_2008.pdf>. Acesso em: 10 mar. 2018.

ARETIO, L. G. Indicadores para la evaluación de la enseñanza en una universidad a distancia. Ried, Madri, v. 1, n. 1, p. 210, jun., 1998. Disponível em: <http://www.utpl.edu.ec/ried/images/pdfs/volumen1-1.pdf>. Acesso em: 20 jun. 2018. BELLONI, M. L. Educação a distância. 5. ed. Campinas: Autores Associados, 2009. Educação a distância. Campinas: Autores Associados, 2001.

Ensaio sobre a educação a distância no Brasil. Educação \& Sociedade, ano XXIII, n.78, abr., 2003.

BIAZUS, C. A. Sistema de fatores que influenciam o aluno a evadir-se dos cursos de graduação na UFSM e na UFSC: um estudo no curso de Ciências Contábeis. 2004 152 f. Tese (Doutorado)-Programa em Engenharia de Produção, Universidade Federal de Santa Catarina, 2004.

CERVO, Amando Luiz; BERVIAN, Pedro Alcino. Metodologia científica. São Paulo: 
Makron Books, 1996.

COElHO, M. L. A Evasão nos Cursos de Formação Continuada de Professores Universitários na Modalidade de Educação a Distância Via Internet. 2002. Disponível em: <http//www.dominiopublico.gov.br/download/texto/me001420.pdf>. Acesso em: 03

Jun 2018.

CHURCHILL Jr., G. A. Marketing research: methodological foundations. Chicago: The Dryden Press, 1987.

FAVERO, R. V. Dialogar ou evadir: eis a questão: um estudo sobre a permanência e a evasão na educação a distância no estado do Rio Grande do Sul. 2006. Dissertação (Mestrado) -Programa de Educação a Distância, Universidade Federal do Rio Grande do Sul, Porto Alegre, 2006.

GIL, A. C. Métodos e técnicas de pesquisa social. 5.ed. São Paulo: Atlas, 1999.

GAIOSO, N. P. O fenômeno da evasão escolar na educação superior no Brasil. 2005. Dissertação (Mestrado em Educação) - Programa de Pós-Graduação em Educação da Universidade Católica de Brasília, Brasília, 2005.

GARSCHAGEN, S. O dilema da repetência e da evasão. 2007. Disponível em: <http://desafios2.ipea.gov.br/sites/000/17/edicoes/36/pdfs/rd36not05.pdf>. Acesso em: 15 mar. 2018.

INEP. Censo da Educação Superior 2015 - Resumo Técnico. Disponível em: $<$ http://download.inep.gov.br/educacao_superior/censo_superior/resumo_tecnico/resum o_tecnico_censo_da_educacao_superior_2015.pdf>. Acesso em: $28 \mathrm{dez} .2017$.

JENSEN, L. F.; ALMEIRA, O. C. A correlação entre falta de interatividade e evasão em cursos a distância. 2009. Disponível em: <http://www.abed.org.br/ congresso2009/CD/.../452009151730.pdf>. Acesso em: 23 fev. 2018.

KUZUYABU, Marina. Educação a distância vive bom momento com a expansão do número de matriculados. 2017.2 Disponível em: $<$ http://www.revistaeducacao.com.br/educacao-distancia-vive-bom-momento-comexpansao-do-numero-de-matriculados/> . Acesso em: 11 ago. 2018. MALHOTRA, N. Pesquisa de marketing. 3.ed. Porto Alegre: Bookman, 2001. 
MOTEJUNAS, P. R. et al. A evasão do ensino superior brasileiro. 2007. Disponível em: http://www.scielo.br/pdf/cp/v37n132/a0737132.pdf> . Acesso em: 20 ago. 2018. NEVES, Y. P. Evasão nos cursos a distância curso de extensão TV na Escola e os Desafios de Hoje. Dissertação (Mestrado)-Programa de Pós-Graduação em Educação Brasileira, Universidade Federal de Alagoas, Alagoas, 2006.

PACHECO, A. S. Evasão: análise da realidade do curso de graduação em Administração a Distância da Universidade Federal de Santa Catarina. Dissertação (Mestrado)-Programa de Pós-Graduação em Administração, Universidade Federal de Santa Catarina, Santa Catarina, 2007.

PACHECO, A. S; MELO, P. A.; MORETTO NETO, L. Evasão na modalidade a distância. 2007.

PETERS, O. A educação à distância em transição. São Leopoldo: Unisinos, 2004.

PEREIRA, F. C. Determinantes da evasão de alunos e os custos ocultos para as instituições de ensino superior: uma aplicação na universidade do extremo sul catarinense. Tese (Doutorado)-Programa de Pós-Graduação em Engenharia de Produção. Universidade Federal de Santa Catarina, Santa Catarina, 2003.

RUMBLE, G. A gestão dos sistemas de ensino a distância. Brasília, DF: Universidade de Brasília; UNESCO, 2003.

SANTOS, Elaine Maria dos, et al. Evasão na Educação a Distância: identificando causas e propondo estratégias de prevenção, 2008. Disponível em: <http://www.abed.org.br/congresso2008/tc/511200845607PM.pdf >Acesso em: 11 de jun.

2018.

SHIN, N.; KIM, J. An exploratory of learner progress and dropout in Korea National Open University. Distance Education, v. 20, n. 3, p. 81-95, 1999. Disponível em:

<https://pdfs.semanticscholar.org/bbe4/e07f8fa35586abeb603d3c1adb2fb63b9c1d.pdf>. Acesso em: 10 mar. 2018.

SILVA FILHO, R. L. et al. A evasão no ensino superior brasileiro. Caderno de Pesquisa, Rio de Janeiro, v. 37, n. 132, p. 641-659, dez., 2007.

TOCZEK, J. et al. Uma visão macroscópica da evasão no ensino superior a distância do Brasil. Disponível em: 
<http://200.169.53.89/download/CD\%20congressos/2008/V\%20ESUD/trabs/t38849.pdf .> . Acesso em: 10 maio 2018.

TOKARNIA, Mariana. Agência Brasil. Educação superior cresce em ritmo acelerado, 2017. Disponível em: <http://agenciabrasil.ebc.com.br/educacao/noticia/2017-

05/educacao-superior-distancia-cresce-em-ritmo-acelerado-mostra-censo-de-2015>.

Acesso em: 14 ago. 2018.

UMEKAWA, Elienay Eiko Rodrigues e ZERBINI, Thaís. Dropping out and persistence in distance education actions: analysis of the student profile. Rev. Psicol., Organ. Trab. [online]. 2015, vol.15, n.2, pp. 188-200. ISSN 19846657. Disponível em: <http://dx.doi.org/10.17652/rpot/2015.2.517> Acesso em: 11 mai. 2018.

UNESCO. Términos de referencia para estudios nacionales sobre repitencia $\mathbf{y}$ eserción en la educación superior en america latina y el Caribe. 2004. Disponível em: 〈http://unesdoc.unesco.org/images/0014/001400/140087s.pdf> Acesso em: 10 jun. 2018.

XENOS, M.; PIERRAKEAS, C.; PINTELAS, P. A survey on student dropout rates and

dropout causes concerning the students in the Course of Informatics of the Hellenic Open University. Computers \& Education, v. 39, n. 4, p. 361-377, 2002. Disponível em: $<$ http://citeseerx.ist.psu.edu/viewdoc/download?doi=10.1.1.320.4739\&rep=rep1\&type= pdf> . Acesso em: 12 nov. 2017.

ZERBINI, T. Estratégias de aprendizagem, reações aos procedimentos de um curso via

Internet, reações ao tutor e impacto do treinamento no trabalho. 2003. Dissertação (Mestrado em Psicologia) - Instituto de Psicologia, Universidade de Brasília, Brasília, 2003.

ZERBINI, T.; ABBAD, G. Qualificação profissional a distância: ambiente de estudo e procedimentos de interação - validação de uma escala. 2008. Disponível em: <http://www.scielo.br/pdf/paideia/v20n47/a04v20n47.pdf> . Acesso em: 19 fev. 2018. 


\section{Rafael Alves Pedrosa}

Graduado em Administração (UNIP), Comércio Exterior (USJT), Gestão Portuária (USJT) e Logística e Transportes (USJT). Pós Graduado em Docência do Ensino Superior (FGV), Gestão de Comércio Exterior e Logística (USJT). Mestre em Gestão de Sistemas Costeiros pela (UNISANTA). Doutorando em Planejamento e Gestão pela Universidade Federal do ABC (UFABC). É docente de ensino superior há 10 anos, com atuação nas seguintes universidades: UFABC, UNIBR, UNISANTA e USJT e coordenador de cursos de Pós Graduação (Lato Sensu).

\section{Danilo Nunes}

Graduado em Administração (UNILUS). Pós Graduado em Produção e Qualidade (FECAP), Recursos Humanos e Planejamento (UNIMONTE). Mestre em Administração pela (UNIMONTE). Doutorando em Administração pela Pontifícia Universidade Católica (PUC-SP). Coordenador de cursos de graduação e pós graduação, Diretor da faculdade UNIBR e exerceu o cargo de Pró Reitor acadêmico da UNIMONTE.

\section{Para citar este trabalho:}

PEDROSA, Rafael Alves; NUNES, Danilo. O DESAFIO DA EVASÃO EM CURSOS SUPERIORES NA MODALIDADE EaD. Revista Paidéi@. Unimes Virtual. Volume.11 - Número 20 - JULHO- 2019 - Disponível em:

http://periodicos.unimesvirtual.com.br/index.php/paideia/index 